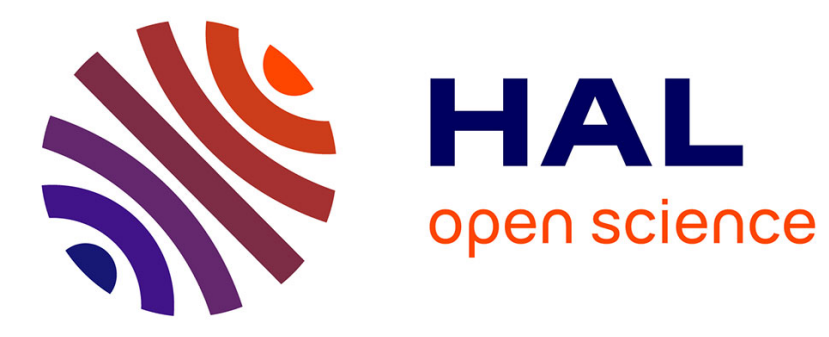

\title{
Econazole imprinted textiles with antifungal activity
}

Mirza Akram Hossain, Fabrice Pagniez, Aicha Benhaddou, Martine Raymond, Karine Théberge, Patrice Le Pape, Pierre Simard, Jeanne Leblond, Augustine Lalloz

\section{- To cite this version:}

Mirza Akram Hossain, Fabrice Pagniez, Aicha Benhaddou, Martine Raymond, Karine Théberge, et al.. Econazole imprinted textiles with antifungal activity. European Journal of Pharmaceutics and Biopharmaceutics, 2016, 10.1016/j.ejpb.2016.02.003 . hal-02512446

\section{HAL Id: hal-02512446 https://hal.science/hal-02512446}

Submitted on 23 Mar 2020

HAL is a multi-disciplinary open access archive for the deposit and dissemination of scientific research documents, whether they are published or not. The documents may come from teaching and research institutions in France or abroad, or from public or private research centers.
L'archive ouverte pluridisciplinaire HAL, est destinée au dépôt et à la diffusion de documents scientifiques de niveau recherche, publiés ou non, émanant des établissements d'enseignement et de recherche français ou étrangers, des laboratoires publics ou privés. 


\section{Econazole Imprinted Textiles with Antifungal Activity}

2 Mirza Akram Hossaina, Augustine Lalloza, Aicha Benhaddoub, Fabrice

3 Pagniezc, Martine Raymond ${ }^{d}$, Patrice Le Papec, Pierre Simard ${ }^{b}$, Karine

$4 \quad$ Théberge $^{\mathrm{b}}$, and Jeanne Leblond ${ }^{\mathrm{a}}$

5

6 a Faculty of Pharmacy, Université de Montréal, PO Box 6128 Station Centre-

7 Ville, Montreal, QC, H3C 3J7, Canada.

8 b Biomod Concepts Inc, Sainte-Julie, QC, J3E 1Y6, Canada.

9 c Département de Parasitologie et de Mycologie Médicale, Université de

10 Nantes, Nantes Atlantique Universités, EA 1155 - IICiMed, Faculté de

11 Pharmacie, Nantes, France ; Laboratoire de Parasitologie-Mycologie, CHU de

12 Nantes, Nantes, France

13 d Institute for Research in Immunology and Cancer and Department of

14 Biochemistry and Molecular Medicine, Université de Montréal, Montreal, QC,

15 H3C 3J7, Canada

16

17 Corresponding author: Łeanne.leblond-chain@umontreal.ca; + (1) 514-343-

18 6455, Faculty of Pharmacy, Université de Montréal, PO Box 6128 Station

19 Centre-Ville, Montreal, QC, H3C 3J7, Canada.

20 Keywords 
21 Econazole nitrate; fungal infection, topical administration; thermo-responsive

22 formulation; lipid microparticles; candida.

\section{Abstract}

24 In this work, we propose pharmaceutical textiles imprinted with lipid 25 microparticles of Econazole nitrate (ECN) as a mean to improve patient

26 compliance while maintaining drug activity. Lipid microparticles were

27 prepared and characterized by laser diffraction $(3.5 \pm 0.1 \mu \mathrm{m})$. Using an

28 optimized screen-printing method, microparticles were deposited on textiles,

29 as observed by Scanning Electron Microscopy. The drug content of textiles

$30\left(97 \pm 3 \mu \mathrm{g} / \mathrm{cm}^{2}\right)$ was reproducible and stable up to 4 months storage at

$3125^{\circ} \mathrm{C} / 65 \%$ Relative Humidity. Imprinted textiles exhibited a thermosensitive

32 behavior, as witnessed by a fusion temperature of $34.8^{\circ} \mathrm{C}$, which enabled a

33 larger drug release at $32^{\circ} \mathrm{C}$ (temperature of the skin) than at room

34 temperature. In vitro antifungal activity of ECN textiles was compared to

35 commercial 1\%(w/w) ECN cream Pevaryl ${ }^{\circledR}$. ECN textiles maintained their

36 antifungal activity against a broad range of Candida species as well as major

37 dermatophyte species. In vivo, ECN textiles also preserved the antifungal

38 efficacy of ECN on cutaneous candidiasis infection in mice. Ex vivo

39 percutaneous absorption studies demonstrated that ECN released from

40 pharmaceutical textiles concentrated more in the upper skin layers, where the

41 fungal infections develop, as compared to dermal absorption of Pevaryl ${ }^{\circledR}$. 
42 Overall, these results showed that this technology is promising to develop

43 pharmaceutical garments textiles for the treatment of superficial fungal

44 infections.

\section{1. Introduction}

47 Textile is a material that has been purposed to clothing for centuries. In

48 recent years, the combined efforts of chemists, textile engineers and

49 cosmetologists resulted in the development of biofunctional textiles that bring

50 additional functions to garments than simple warmth and body protection.

51 Also called cosmetotextiles, such textiles are defined as textile items containing

52 substance or mixture that release their active compounds when in contact with

53 the human body [1]. Firstly focused on improved comfort, cosmetotextiles

54 have since then been developed for slimming, moisturizing, and perfuming [2].

55 Innovative technologies have been incorporated into such fabrics, such as

56 microencapsulated substances $[1,3]$ or phase change materials that help the

57 thermoregulation of the body [4]. Rapidly, various biofunctional textiles have

58 been envisioned for the delivery of topical bioactive molecules, since the close

59 and prolonged contact of fabric with the skin could make cloth an easy drug

60 delivery system. Silver nanoparticles [5] and chitosan [6] were used as

61 preservatives for antibacterial clothing. Fabrics with antioxidant properties 
62 were developed by incorporation of vitamin E [7] or gallic acid [8]. Some

63 clinical indications have also been examined, such as venous insufficiency

64 using aescin supported textiles [9] and atopic dermatitis with zinc oxide

65 functionalized textiles [10]. Such examples show the evolution of cosmeto-

66 textiles to pharmaceutical textiles, offering more than an improved comfort,

67 but also a treatment for various skin diseases.

68 In particular, superficial fungal diseases are common worldwide and

69 their incidence continues to increase. In 2010 , they were the $4^{\text {th }}$ most prevalent

70 disease in the world, affecting more than 948 million people worldwide [11].

71 As compared to bacteria, fungal topical infections are longer in duration and

72 require weeks and even months of fastidious treatment. Patient compliance

73 would be greatly improved if a regular piece of textile (such as bandage or

74 socks) could be used instead of applying a cream daily. Antifungal textiles have

75 been prepared by soaking the fabric into a solution of antifungals $[12,13]$, and

76 promising clinical results have been obtained from a sock prototype to treat

77 tinea pedis [14]. However, fabrication technology and controlled release of

78 antifungal agents still need to be improved.

79 Econazole Nitrate (ECN) is currently marketed for the treatment of

80 vaginal candidiasis and topical fungal infections as a cream formulation [15,

81 16]. It has demonstrated antifungal activity against Candida and

82 dermatophytes species [15-17]. Encapsulation of ECN in lipid particles [18], 
83 microspheres [19], and micelles [20] has been reported to improve cutaneous

84 efficacy of ECN. More precisely, comparing micro- and nano- solid lipid

85 particles, nanoparticles were shown to improve transdermal administration

86 whereas microparticles enhanced skin deposition [21]. Moreover, the lipid

87 composition favored a good biocompatibility of the particles and improved

88 skin penetration of the drug [22].

89 In this work, a novel ECN formulation on textile support was tested as a

90 proof of concept for the treatment of topical fungal infections. The formulation

91 is based on proprietary lipid microparticles exhibiting thermosensitivity in

92 order to release the drug on contact with the skin [23]. Deposition of the

93 microparticles on textile is achieved using an in-house modified screen-

94 printing technique. The latter is a simple method where the microparticles are

95 passed through a mesh with predefined openings to control the amount and

96 the topology of the deposit [24, 25]. This method allows for a physical uniform

97 deposit of the microparticles at specific areas on textiles without addition of

98 chemical binders. The solid microparticles (Dermotex®) and deposition

99 method $\left(\mathrm{On} 2^{\mathrm{TM}}\right)$ are technologies proprietary to Biomod Concepts Inc., and

100 have been used by the company to produce intelligent cosmetic textiles [23].

101 The objective of this study is to evaluate the potential of a pharmaceutical

102 textile, namely a microparticle formulation of ECN deposited on textile. Its in

103 vitro antifungal activity, percutaneous absorption, and in vivo pharmaceutical 
104 efficacy on a superficial fungal infection were compared to the commercial $1 \%$

$105(w / w)$ ECN cream Pevaryl ${ }^{\circledR}$.

106

107 2. Experimental methods

108 2.1. Materials

109 ECN-loaded microparticles on textile and all placebo textile formulations were

110 provided by Biomod Concepts Inc. (Ste-Julie, QC, Canada) and prepared

111 according to their patented technology [23]. Laya ${ }^{\mathrm{TM}}$ textiles were provided by

112 Biomod Concepts (Sainte-Julie, QC, Canada). ECN was purchased from AK

113 Scientific (Union City, CA, USA, Lot\# TC24717). Pevaryl ${ }^{\circledR}$ 1\% (w/w) ECN

114 formulation was purchased from Johnson \& Johnson (France, Lot \# DDB3400)

115 and its generic version from Mylan Pharmaceuticals (Saint-Priest, France).

116 Miconazole Nitrate was purchased from AK Scientific (Union City, CA, USA,

117 Lot\# TC25782). ECN standard disks were purchased from Rosco (Neo-

118 sensitabs $10 \mu \mathrm{g}$ disks, Denmark, Lot \#1201-1). Prednisolone acetate was

119 purchased from Sanofi Aventis (Paris, France) Polyethylene Glycol 400 (PEG-

120 400) was purchased from Medisca Inc. (Montreal, QC, Canada). Sodium dodecyl

121 sulfate (SDS) and semi-permeable polycarbonate membranes (Nucleopore

122 Track-Etch Membrane, pores of $0.6 \mu \mathrm{m}, 25 \mathrm{~mm}$ in diameter) were purchased

123 from Sigma-Aldrich (Oakville, ON, Canada). Tape used for tape stripping was

124 purchased from 3M tape (St-Paul, MN, USA). All samples were filtered using 
125 PTFE filters purchased from Fisher Scientific (EMD Millipore Millex, pores 0.45

$126 \mu \mathrm{m}, 13 \mathrm{~mm}$ in diameter, Ottawa, ON, Canada). All solvents (HPLC grade) were

127 bought from Fisher Scientific (Ottawa, ON, Canada).

$128 \quad 2.2$ Organisms

129 Candida albicans strain SC5314 was originally isolated from a patient with

130 disseminated candidiasis, and served as reference for the $C$. albicans genome

131 sequencing project $[26,27]$. Thirteen clinical isolates of Candida spp. and $C$.

132 albicans (CAAL93, CAAL121, CAAL123, CAAL124, CAAL294), C. kefyr (CAKE3,

133 CAKE4), C. krusei (CAKR1, CAKR3), C. glabrata (CAGL1,CAGL5), and C.

134 Iusitaniae (CALU1, CALU2) were obtained from the Department of Parasitology

135 and Medical Mycology, EA1155, at the University of Nantes, France.

136 Trichophyton rubrum $(\mathrm{n}=2)$ and T. mentagrophytes $(\mathrm{n}=2)$ were obtained from

137 the Laboratory of Parasitology and Medical Mycology at the Centre Hospitalier

138 Universitaire of Nantes.

\section{2.3. Preparation of ECN textiles}

140 Intelligent textiles imprinted with ECN-loaded microparticles were prepared

141 by Biomod Concepts Inc. using their patented technology [23]. Briefly, ECN

142 lipid microparticles $(1 \% w / w)$ were prepared under high shear using FDA-

143 approved ingredients. The microparticles formulation was then applied onto

144 textile surface using an adapted screen-printing method optimized for the

145 microparticles deposition. A stencil with openings of more than $400 \mu \mathrm{m}$ was 
146 used to apply the microparticles on $21.6 \times 27.9 \mathrm{~cm}$ pieces of a polyester non-

147 woven textile provided by Biomod Concepts Inc. ECN imprinted textiles were

148 kept at $22^{\circ} \mathrm{C}$ in sealed aluminum/acrylonitrile-coated packagings until 149 analysis.

\section{2.4. Characterization of microparticles}

151 One hundred milligram (100 $\mathrm{mg})$ of the ECN-loaded microparticles

152 preparation used for screen-printing was diluted in $5 \mathrm{~mL}$ of milliQ water and

153 analyzed for article size distribution at $22^{\circ} \mathrm{C}$ by laser diffraction (LS 13320 ,

154 Beckman Coulter, Mississauga, ON, Canada). Pevaryl ${ }^{\circledR}$ particle size was

155 measured by dynamic light scattering (Zetasizer Nano ZS, Malvern,

156 Worcestershire, UK) using the automatic algorithm mode. Samples were

157 prepared by diluting $100 \mathrm{mg}$ of Pevaryl ${ }^{\circledR}$ in $5 \mathrm{~mL}$ of MilliQ water, position 4.65

158 and attenuator at 8. Measurements were recorded 3 times for each 159 formulation.

160 Fusion temperature of the microparticles imprinted on textile was measured

161 using thermal analysis based on heat-leak-modulus (TA-HLM) [28]. With TA-

162 HLM, textile samples are wrapped around a sensor probe and heated. The

163 samples of ECN-loaded textile $(2.5 \times 5 \mathrm{~cm})$ were analyzed at a heating rate of

$1640.8^{\circ} \mathrm{C}$ per second and heated from $0^{\circ} \mathrm{C}$ to $100^{\circ} \mathrm{C}$. Measurement was repeated 3

165 times.

$166 \quad 2.5$ HPLC-UV analysis 
167 High-performance liquid chromatography (HPLC) with ultraviolet (UV)168 analysis was used for stability and quantification of samples.

169 The HPLC-UV system (Agilent 1100 Series, Mississauga, ON, Canada) consisted

170 in a degasser, dual pumps, auto-sampler, column heater and photo-diode array

171 detector. A C18 column ( $25 \times 4.6 \mathrm{~mm}, 5 \mu \mathrm{m}$ packing, Zorbax-C18, Agilent, Santa

172 Clara, CA, USA) was used with a matching pre-column (Agilent Zorbax C18).

173 Mobile phase was composed of methanol and water using the gradient detailed

174 in Table 1.

175 The flow rate was $1.4 \mathrm{~mL}$ per minute. The column temperature was set to $35^{\circ} \mathrm{C}$.

176 The injection volume was $20 \mu \mathrm{L}$. ECN was analyzed at $220 \mathrm{~nm}$. ECN retention

177 time was 8.7 minutes. The limit of quantification with this method is $9 \mu \mathrm{g} / \mathrm{mL}$. 178

179 Table 1: Gradient of solvents in the HPLC-UV system

\begin{tabular}{ccc}
\hline Time (min) & Water (\%) & Methanol (\%) \\
\hline 0 & 43 & 57 \\
\hline 3 & 28 & 72 \\
\hline 6 & 2 & 98 \\
\hline 10 & 2 & 98 \\
\hline 13 & 43 & 57 \\
\hline 15 & 43 & 57 \\
\hline
\end{tabular}

180

1812.6 HPLC-MS/MS method 
182 HPLC-Mass spectrometry (MS)/MS was used for in vitro release and ex vivo

183 experiments on pig skin, which presented lower concentrations of ECN than

184 the limit of quantification (LOQ) of HPLC-UV method. An Agilent 1100 series

185 HPLC (Mississauga, ON, Canada) was coupled to a 4000Q TRAPTM (AB Sciex,

186 Concord, ON, Canada) hybrid triple-quadrupole/linear ion trap MS. All the

187 parameters can be found in Table 2. Each sample was injected twice. HPLC-

188 MS/MS method was developed and validated for ECN, using miconazole nitrate

189 as an internal standard. No matrix effect was found with any components of

190 the skin.

191

192 Table 2: LC-MS/MS parameters

\begin{tabular}{|c|c|c|c|c|}
\hline HPLC & \multicolumn{4}{|c|}{ Agilent 1100 series } \\
\hline MS/MS & \multicolumn{4}{|c|}{ AB Sciex 4000 Qtrap } \\
\hline Software & \multicolumn{4}{|c|}{ Analyst $\AA$ (version 1.6.2) } \\
\hline Ionisation & \multicolumn{4}{|c|}{ Turbo electrospray, positive ionization (ESI) } \\
\hline Scan mode & \multicolumn{4}{|c|}{ Multiple reaction monitoring (MRM) } \\
\hline $\begin{array}{l}\text { Analyte } \\
\text { parameters }\end{array}$ & Compounds & DP (V) & MRM & CE $(\mathrm{eV})$ \\
\hline Test molecule & \multicolumn{2}{|l|}{ Econazole } & \multicolumn{2}{|l|}{$381>125$} \\
\hline $\begin{array}{l}\text { Internal } \\
\text { Standard }\end{array}$ & \multicolumn{2}{|l|}{ Miconazole } & $417>161$ & 40 \\
\hline \multirow{4}{*}{$\begin{array}{l}\text { Source } \\
\text { parameters }\end{array}$} & Gas temp $\left({ }^{\circ} \mathrm{C}\right)$ & \multicolumn{3}{|l|}{650} \\
\hline & Gas flow (L/min) & \multicolumn{3}{|l|}{50} \\
\hline & Curtain gas (psi) & \multicolumn{3}{|l|}{25} \\
\hline & Capillary (V) & \multicolumn{3}{|c|}{5500} \\
\hline Mobile phase & Composition & \multicolumn{3}{|c|}{$\begin{array}{l}\text { A: } 0.1 \% \text { Formic Acid }(\mathrm{FA})+\mathrm{H}_{2} \mathrm{O} \\
\text { B: } 0.1 \% \text { Formic Acid + Acetonitrile: } \\
\text { Isopropanol }(80 / 20)\end{array}$} \\
\hline & Gradient & \multicolumn{3}{|c|}{$\begin{array}{l}15 \text { to } 97 \% \text { of phase } B \text { in } 1.5 \mathrm{~min} \text {, then } \\
\text { stay at } 97 \% \text { until } 2.2 \mathrm{~min} \text {, decrease to }\end{array}$} \\
\hline
\end{tabular}




\begin{tabular}{|l|l|l|}
\cline { 2 - 3 } & \multicolumn{1}{c|}{$\begin{array}{l}15 \% \text { at } 2.3 \mathrm{~min} \text { and stay at } 15 \% \text { of } \\
\text { phase B until } 3.5 \mathrm{~min}\end{array}$} \\
\hline Flow rate & $0.7 \mathrm{~mL} \cdot \mathrm{min}^{-1}$ \\
\hline $\begin{array}{l}\text { Column } \\
\text { temperature }\end{array}$ & $45^{\circ} \mathrm{C}$ \\
\hline $\begin{array}{l}\text { Injection } \\
\text { volume }\end{array}$ & $2 \mu \mathrm{L}$ \\
\hline $\begin{array}{l}\text { Injection } \\
\text { temperature }\end{array}$ & $5^{\circ} \mathrm{C}$ \\
\hline Column & $\begin{array}{l}\text { Luna C8 column }(30 \times 2.0 \mathrm{~mm}, 5 \mu \mathrm{m}, \text { Phenomenex, } \\
\text { Torrance, CA, USA })\end{array}$ \\
\hline
\end{tabular}

\section{$194 \quad 2.7$ Quantification of ECN Textile}

195 One-cm² pieces of ECN imprinted textile were sampled from the center region

196 of randomly selected textile sheets for a good statistical analysis. Ten out of the

19730 sheets imprinted for this study were sampled and analyzed. To extract ECN

198 from the fabric, textile samples were suspended in $1 \mathrm{~mL}$ of methanol, sonicated

199 for 30 minutes and heated at $55^{\circ} \mathrm{C}$ for 4 hours. After cooling down, $500 \mu \mathrm{L}$ of

200 the extraction solution was sampled, filtered, and quantified by HPLC-UV.

\section{$201 \quad 2.8$ Stability}

202 Three $15 \times 15 \mathrm{~cm}$ sheets of imprinted ECN textile were placed in a stability 203 chamber $\left(25^{\circ} \mathrm{C} / 65 \%\right.$ relative humidity (RH)). At each time point, three $1-\mathrm{cm}^{2}$

204 pieces were samples per sheet from the center area of the textile for analysis.

205 The sample preparation and quantification methods were as described above 206 (section 2.7). The stability was monitored up to 4 months.

\subsection{In vitro release}


208 Disks of $0.79 \mathrm{~cm}^{2}(10 \mathrm{~mm}$ diameter, containing $71 \mu \mathrm{g}$ of ECN $)$ were cut out of

209 the imprinted textile. In vitro release was performed using Franz cells from

210 PermGear Inc. (Hellertown, PA, USA) with an opening of $9 \mathrm{~mm}$ in diameter, 5

211 mL receptor size and a thermostated jacket. Diffusion tests were carried on

212 semi-permeable polycarbonate membranes of $0.6 \mu \mathrm{m}$ in pore size. The

213 receptor fluid composition was optimized to ensure ECN diffusion was not

214 limited by ECN solubility. Although ECN was not soluble at pH 7.4, its solubility

215 was improved in $10 \mathrm{mM}$ phosphate buffer solution (PBS) with $1.37 \mathrm{mM}$ of $\mathrm{NaCl}$

216 at pH 4.5 with PEG-400 (70:30 v/v) [29]. Indeed, Pevaryl diffusion (20 mg) on

217 Frantz cells using a semi-permeable polycarbonate membranes of $0.6 \mu \mathrm{m}$ in 218 pore size after $6 \mathrm{~h}$ at $32^{\circ} \mathrm{C}, \mathrm{ECN}$ solution recovery was $49.5 \% \pm 1.3$ and

$21913.5 \% \pm 1.3$ with and without PEG, respectively ( $\mathrm{n}=3$ for each condition, data 220 not shown). The receptor fluid (10 $\mathrm{mM}$ phosphate buffer solution (PBS) with

$2211.37 \mathrm{mM}$ of $\mathrm{NaCl}$ at $\mathrm{pH} 4.5$ with PEG-400 $(70: 30 \mathrm{v} / \mathrm{v}))$ was thermostated at $22^{\circ} \mathrm{C}$

222 or $32^{\circ} \mathrm{C}$ and was constantly stirred at $100 \mathrm{rpm}$. Samples of $400 \mu \mathrm{L}$ were

223 withdrawn at 30 minutes, 1, 2, 3, 4, and 6 hours, filtered and replaced with the

224 same volume of receptor fluid. Samples were diluted 1:50 in a mixture of $20 \%$

225 acetonitrile: $80 \% \mathrm{H}_{2} \mathrm{O}$ with $0.1 \%$ FA before quantification by HPLC-MS/MS.

226 2.10 Antifungal Disk Diffusion tests

227 C. albicans SC5314 and Candida strains from Nantes were routinely grown at $22830^{\circ} \mathrm{C}$ in yeast peptone dextrose (YPD; $1 \%$ yeast extract, $2 \%$ Bacto peptone, $2 \%$ 
229 dextrose plus 2\% agar for solid medium) and Sabouraud (SB) culture medium

230 respectively. C. albicans SC5314 were suspended in liquid YPD medium to an

$231 \mathrm{OD}_{600}$ of 0.1 , and $150 \mu \mathrm{L}$ of the cell suspension were spread on YPD Petri dishes

232 (10 cm diameter). Disks of $0.79 \mathrm{~cm}^{2}(10 \mathrm{~mm}$ diameter, containing $71 \mu \mathrm{g}$ of ECN)

233 were cut out of the imprinted textile, and equivalent quantity of Pevaryl ${ }^{\circledR}$ (7.1

$234 \mathrm{mg}$ Pevaryl ${ }^{\circledR}, 71 \mu \mathrm{g}$ ECN) was weighed on a filter paper disk (10 mm in

235 diameter). Placebo textiles imprinted with drug-free microparticles and

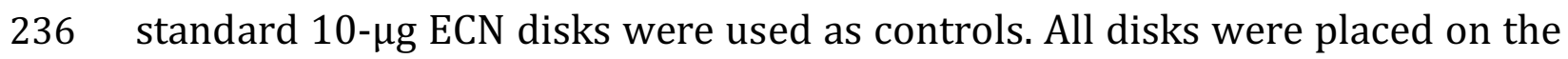

237 YPD Petri plates. The plates were incubated at $32^{\circ} \mathrm{C}$, and growth inhibition

238 diameters were measured at $18 \mathrm{~h}$. This was replicated 9 times for each

239 formulation and repeated 3 times independently.

240 Other Candida spp isolates were suspended in sterile saline $(0.85 \% \mathrm{NaCl})$ to

241 achieve $1 \times 10^{6}$ cells per $\mathrm{mL}$, which were deposited onto SB Petri dishes $(10 \mathrm{~cm}$

242 in diameter). Disks of $0.50 \mathrm{~cm}^{2}$ ( $8 \mathrm{~mm}$ in diameter, containing $50 \mu \mathrm{g}$ of ECN)

243 were cut out of the imprinted textile, and equivalent quantity of Pevaryl ${ }^{\circledR}(5.0$

244 mg Pevaryl ${ }^{\circledR}, 50 \mu \mathrm{g}$ ECN) was weighed on a filter paper disk (8 mm in

245 diameter). Placebo textiles (8 $\mathrm{mm}$ in diameter) and standard $10-\mu \mathrm{g}$ ECN disks

246 were used as controls. All disks were placed on the SB Petri plates. The plates

247 were incubated at $35^{\circ} \mathrm{C}$ and growth inhibition diameters were measured at

248 18h. This was replicated 4 times for each formulation and repeated 2 times

249 independently. 
250 Trichophyton rubrum and T. mentagrophytes were grown on SB culture

251 medium. Trichophyton species were suspended in sterile saline $(0.85 \% \mathrm{NaCl})$

252 with $0.1 \%$ SDS to achieve $1 \times 10^{6}$ fungal cells per $\mathrm{mL}$, and the cells deposited

253 on SB petri dishes ( $10 \mathrm{~cm}$ in diameter $)$. The plates were incubated at $25^{\circ} \mathrm{C}$, and

254 growth inhibition diameters were measured after 4 days for T. mentagrophytes

255 and after 7 days for T. rubrum. This was replicated 3 times for each formulation

256 and species. This was repeated 3 times independently for T. mentagrophytes

257 and once for T. rubrum.

\section{$258 \quad 2.11$ Ex vivo diffusion test on pig ear skin}

259 Pig ears were kindly provided by Dr. Fairbrother from the Veterinary 260 Department of Université de Montréal (Saint-Hyacinthe, QC, Canada). Ears 261 were washed with water and 1\% SDS and shaved using a razor. The skin was 262 gently peeled off from the dorsal region of the ears, washed again with $1 \%$ SDS 263 and water and stored at $-20^{\circ} \mathrm{C}$ until the next day. Skin diffusion tests were 264 performed using Franz cells as described above. The receptor fluid was 265 identical to in vitro release studies. It contained $10 \mathrm{mM}$ PBS at pH 4.5 with $30 \%$ 266 PEG-400, to ensure ECN solubility, and was stirred at $100 \mathrm{rpm}$ [29]. The 267 receptor compartments were heated to $37^{\circ} \mathrm{C}$ to help maintain the surface of 268 the skin at $32^{\circ} \mathrm{C}$. Disks of $0.79 \mathrm{~cm}^{2}(10 \mathrm{~mm}$ in diameter, containing $71 \mu \mathrm{g}$ of 269 ECN) were cut out of the imprinted textile, and equivalent quantity of Pevaryl ${ }^{\circledR}$ 270 (7.1 mg, $71 \mu \mathrm{g}$ ECN) was weighted on a filter paper disk (10 $\mathrm{mm}$ in diameter). 
271 The disks were applied upside down on the surface of the skin, so that the

272 formulation was in direct contact with the skin. A small weight (5 g) was

273 applied in order to ensure contact between the formulation and the skin

274 surface. The system was dismounted after 24 hours and all the receptor fluid

275 was collected. The used textiles and filter paper disks were collected for ECN

276 quantification. The skin surface was washed with $8 \mathrm{~mL}$ of ethanol/water

277 (50:50), which was collected for ECN quantification. The skin was separated in

2783 layers: stratum corneum (SC), epidermis and dermis. The SC was removed

279 using 20 strips of $1 \mathrm{~cm}^{2} 3 \mathrm{M}$ tape, which was extracted with $20 \mathrm{~mL}$ of

280 acetonitrile. Epidermis was peeled off from the dermis after heating at $80^{\circ} \mathrm{C}$ for

28110 seconds. Both epidermis and dermis were cut into pieces and were

282 suspended in $1 \mathrm{~mL}$ acetonitrile. All samples were sonicated for $30 \mathrm{~min}$ then

283 heated at $55^{\circ} \mathrm{C}$ for 4 hours. Liquid layers were filtered and diluted with $20 \%$

284 acetonitrile with $0.1 \%$ FA. Samples were diluted (1:20 for epidermis, 1:200 for

285 residual formulation on filter paper disks and textiles, and 1:10 for washing,

286 SC, dermis, and receptor fluid) and quantified by HPLC-MS/MS. The Overall

287 recovery of ECN (sum of residual textile, washing, SC, epidermis, dermis) was

$28897.7 \% \pm 5.7(n=9)$. Skins from 3 different pig ears were tested in triplicate 289 each $(n=9)$.

$290 \quad 2.12$ Cutaneous candidiasis model in immunosuppressed mice 
291 Female mice were treated with prednisolone acetate on the day before and on 292 the day after inoculation. Hairs on the back of anesthetized mice were plucked 293 by hand to make a hairless square. The skin was then slightly abraded using 294 sandpaper and Candida albicans inoculum (25 $\mu \mathrm{L}$ at 3. $10^{9}$ yeast/mL) was 295 applied. Mice were then randomly distributed into 4 groups of 6 animals. At 296 day 3 post-infection, treatment was applied topically on the skin lesion once 297 daily during 5 consecutive days. A first group was treated with the reference 298 drug, Mylan ECN cream at a dose of $50 \mu \mathrm{g}$ of ECN per lesion, a second one with 299 a disk of ECN textile at a dose of $50 \mu \mathrm{g}$ of ECN per lesion, a third one with a 300 placebo textile, and a fourth one was untreated and served as control group of 301 the disease.

302 In order to evaluate the infection level, microbiological studies were 303 undertaken. Skin specimens from infected locus were taken with a biopsy 304 punch at day 9 post-infection. Each sample (half of the biopsy) was 305 homogenized in saline solution with a tissue grinder. Dilutions were inoculated 306 on Sabouraud-chloramphenicol-gentamicin agar plates. After a 48-h 307 incubation time at $35^{\circ} \mathrm{C}$, the number of yeast colonies was counted.

308 The procedure was approved by the ethical committee of Pays de la Loire, 309 France with the agreement D44015 for the Unité Thérapeutique 310 Experimentale, Faculté de médecine, Nantes.

\section{$311 \quad 2.13$ Statistical Analysis}


312 Statistical analysis was executed by means of Graph Pad® 6.0c (Prism

313 Software, San Diego, CA, USA). Multiple $t$-test was used with corrected $p$-value

314 using the sidak-bonferroni assuming unequal variance method for ex vivo pig

315 skin diffusion tests. All $p$-values $\leq 0.05$ were considered to be significant.

\section{3. Results and discussion}

318

319

320

321 ECN-loaded lipid microparticles $(1 \% \mathrm{w} / w)$ were prepared under high shear

322 and deposited on textile using a screen-printing method as previously

323 described [23]. The pharmaceutical textiles were first characterized for their

324 ECN content. ECN was extracted from textile samples and analyzed by HPLC.

325 ECN content was measured to be $90 \pm 19 \mu \mathrm{g}$ per $\mathrm{cm}^{2}$. The uniformity and the

326 homogeneity of deposition of ECN-loaded microparticles were assessed from

32710 different sheets of textile and 3 different areas per sheet and was

328 determined to be less than $10 \%$ of the mean ECN value (data not shown).

329 Moreover, the ECN content was monitored as indicator of the chemical stability

330 of the pharmaceutical textiles. Stability was monitored each week during 6

331 weeks and again after 16 weeks using a stability chamber at $25 \mathrm{C}^{\circ} \mathrm{C} / 65 \% \mathrm{RH}$

332 (Table 3). After 4 months, ECN content was still $97 \mu \mathrm{g} / \mathrm{cm}^{2}$, which represents

$333108 \%$ of the initial content. Altogether, the reproducibility of the production 
334 process and the stability over several months demonstrated the potential of

335 the pharmaceutical textiles as new therapeutic products.

336

337 Table 3: ECN content of pharmaceutical textiles upon storage at $25^{\circ} \mathrm{C} / 65 \% \mathrm{RH}$.

$338 \mathrm{~T}_{0}$ : After screen-printing. $(\mathrm{n}=9)$

\begin{tabular}{llllllll}
\hline Time in weeks & $\mathrm{T}_{0}$ & $\mathrm{~T}_{1}$ & $\mathrm{~T}_{2}$ & $\mathrm{~T}_{3}$ & $\mathrm{~T}_{4}$ & $\mathrm{~T}_{6}$ & $\mathrm{~T}_{16}$ \\
\hline $\begin{array}{l}\text { ECN Textile } \\
\text { content }\left(\mu \mathrm{g} / \mathrm{cm}^{2}\right)\end{array}$ & $90 \pm 19$ & $99 \pm 10$ & $105 \pm 11$ & $100 \pm 20$ & $96 \pm 9$ & $84 \pm 2$ & $97 \pm 3$ \\
\hline 339 & & & & & & &
\end{tabular}

340 In a second step, physicochemical properties of the microparticles were

341 examined. Microparticle size was evaluated before deposition on textile using

342 laser diffraction (Figure 1). Particles exhibited micro-range diameter $(3.5 \pm 0.1$

$343 \mu \mathrm{m})$. Pevaryl ${ }^{\circledR}$ particle size was also measured by dynamic light scattering and

344 indicated a mean particle size of $348 \mathrm{~nm}$ with a polydispersity of 0.3 . After

345 screen-printing, ECN textiles were observed by scanning electron microscopy

346 for their size and morphology. Figure 2 shows the presence of microparticles

347 deposited on the textile fibers along with a film surrounding the microparticles.

348 The film could be microparticles that partially melted or fused during the

349 deposition process, probably due to the low fusion temperature of 350 microparticles. 


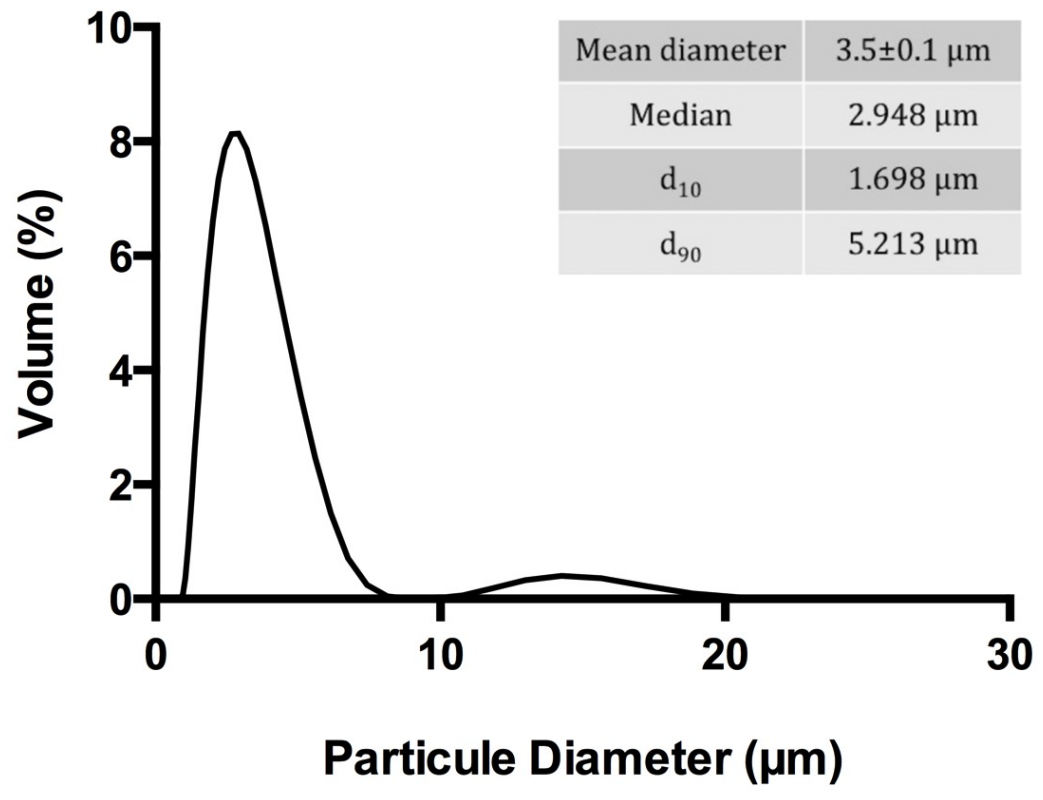

353

354 Figure 1: ECN microparticles size distribution by laser diffraction $(n=9)$.

355

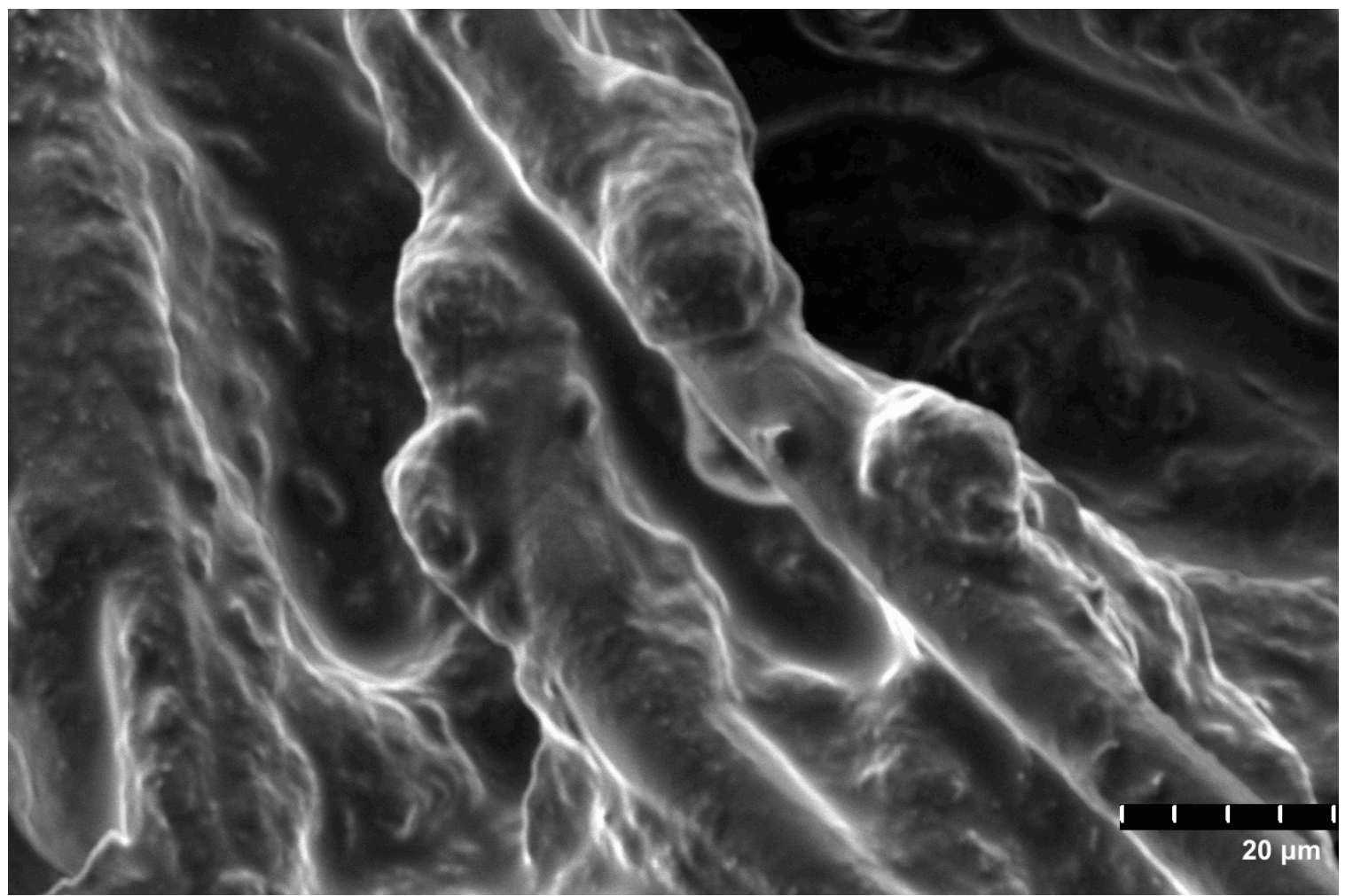


357 Figure 2: Scanning electron microscopy image of ECN pharmaceutical textile.

$358 \quad$ Scale $=20 \mu \mathrm{m}$.

359

360 Lipid microparticles deposited on textile exhibited a fusion temperature of

$36134.8^{\circ} \mathrm{C}$, as determined by TA-HLM, which confirmed their solid character at

362 room temperature (Figure 3). The latter is a method similar to differential

363 scanning calorimetry, which allows for the measurement of fusion

364 temperature of microparticles deposited on a textile surface [28]. This fusion

365 temperature value is crucial to allow triggered release upon contact with the

366 skin, which is at approximately $32^{\circ} \mathrm{C}$, while maintaining a good stability upon

367 storage at room temperature.

368

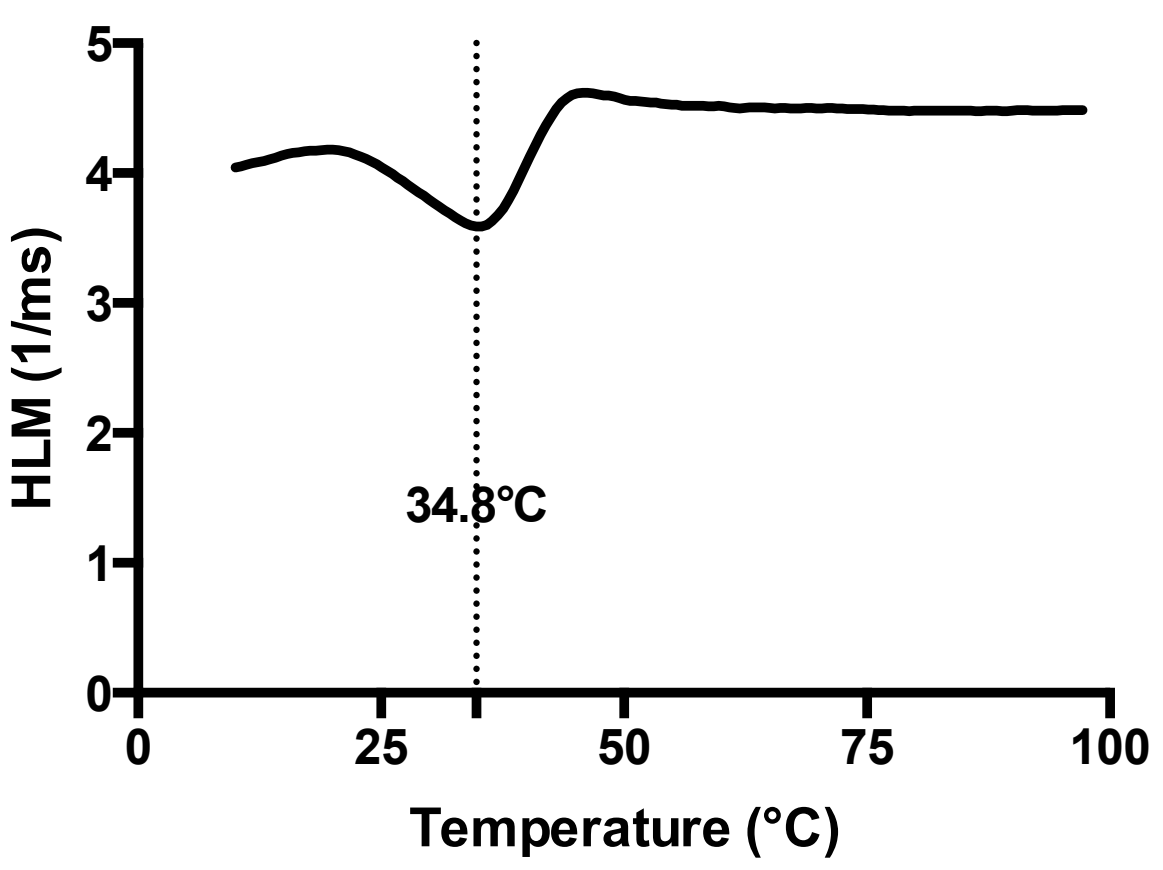

369

370

Figure 3: TA-HLM of ECN textile. 
372 The thermo-sensitive behavior of the pharmaceutical textiles was further

373 confirmed by the drug release profiles obtained at room temperature and at

$37432^{\circ} \mathrm{C}$ in Franz diffusion cells (Figure 4). As expected, release at $32^{\circ} \mathrm{C}$ was higher

375 and faster than at room temperature. Indeed, the textiles released about twice

376 the amount of ECN at all time points (although no significant difference was

377 seen at 6 hours due to larger error bars). Raising the temperature to $32^{\circ} \mathrm{C}$, close

378 to the fusion temperature of the microparticles, initiated the

379 fluidification/fusion of the microparticles and allowed ECN diffusion from the

380 textile. It can be noted that no increase in ECN concentration in receptor fluid

381 was observed after $24 \mathrm{~h}$ (data not shown), indicating that the maximum release

382 was reached within 6 hours. This suggested the textiles served as a reservoir

383 for ECN, since less than $29 \pm 6 \%$ of the total ECN was released. 


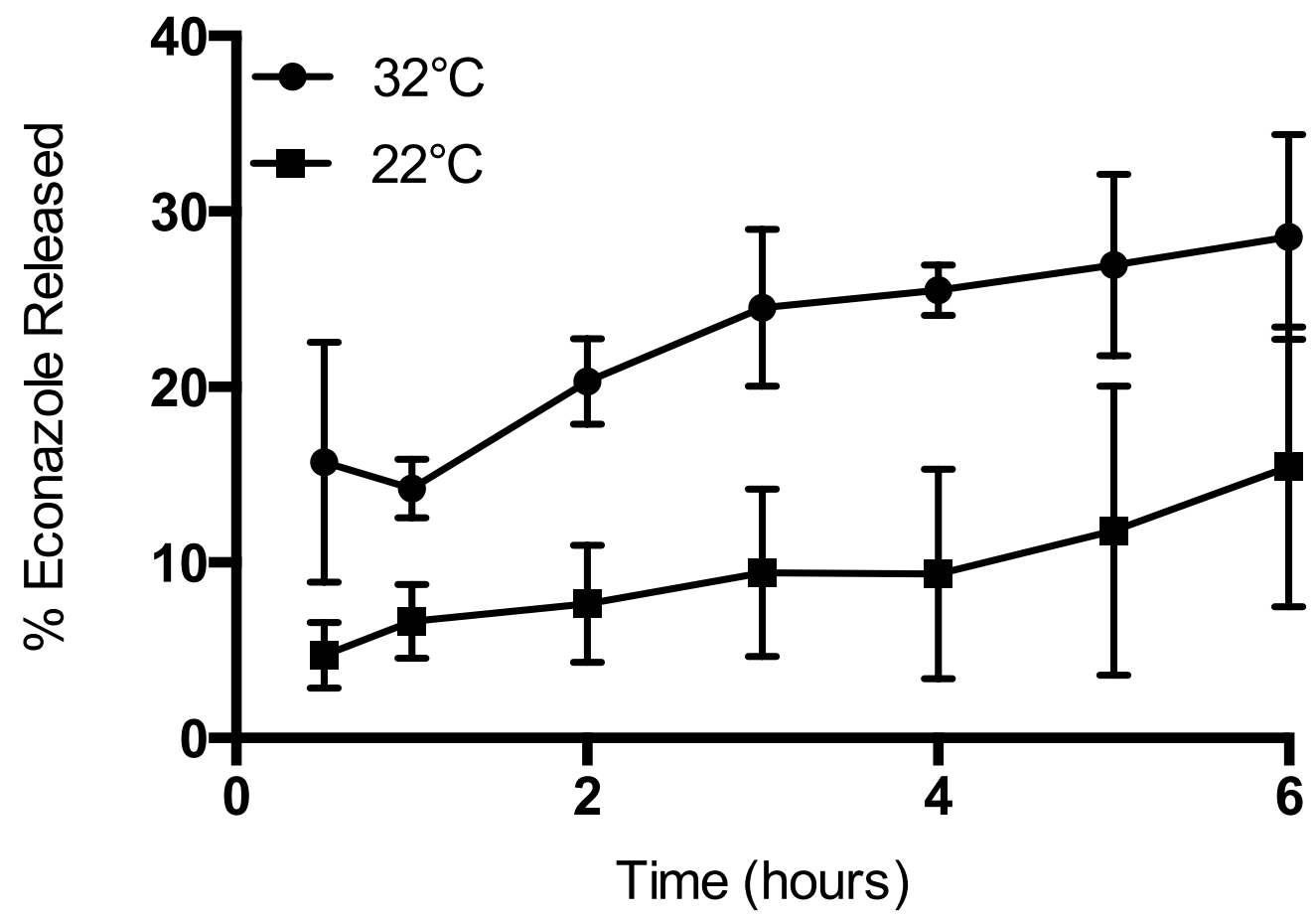

386 Figure 4: ECN release from pharmaceutical textiles at $22^{\circ} \mathrm{C}$ (black squares) and $38732^{\circ} \mathrm{C}$ (black circles) on Franz diffusion cells through polycarbonate 388 membranes. Mean \pm standard error bars $(n=4)$.

\section{$390 \quad 3.2$ Antifungal activity of pharmaceutical textiles}

391 Once their thermo-sensitive behavior was verified, the intelligent textiles were

392 examined to ensure that the developed technology was able to preserve the

393 pharmaceutical activity of the drug. Antifungal activity of ECN textiles was 394 compared to Pevaryl ${ }^{\circledR}$, a commercial formulation of ECN. Pevaryl ${ }^{\circledR}$ is a $1 \%$ $395(w / w)$ ECN cream indicated to treat Candida and dermatophytes superficial 396 infections $[15,16]$. 


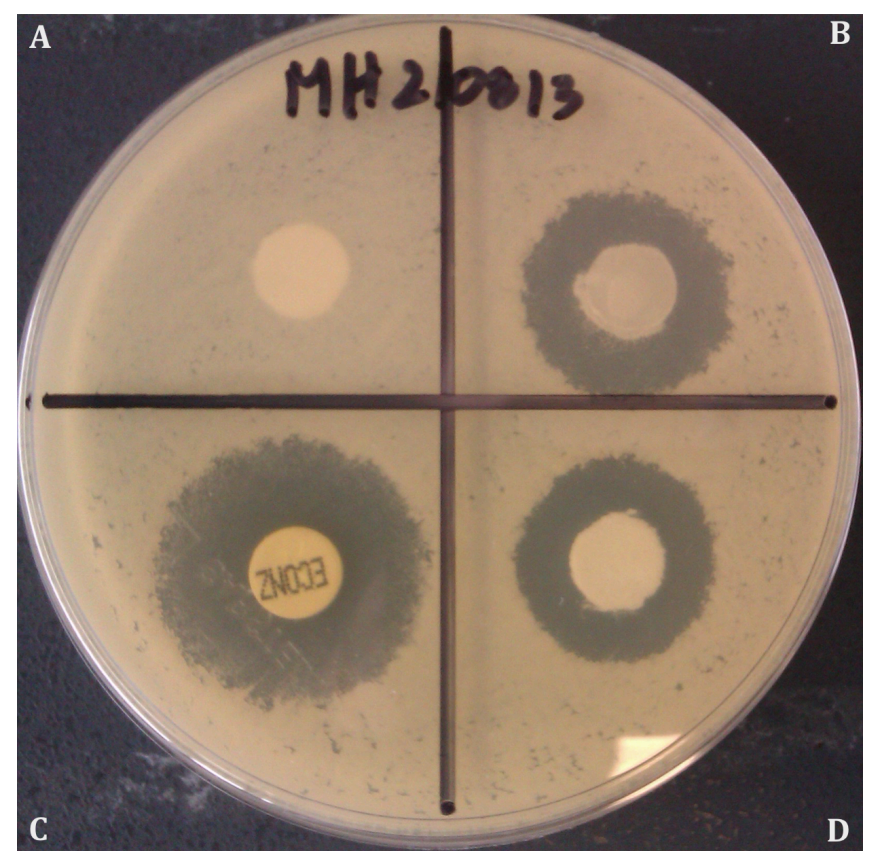

398 Figure 5: Antifungal disk diffusion test on C. albicans SC5314 containing textile 399 placebo (imprinted with blank formulation) (A), Pevaryl ${ }^{\circledR}$ formulation (71 $\mu \mathrm{g}$ 400 ECN) on a filter paper (B), soluble ECN $10 \mu \mathrm{g}$ standard disks (C), and ECN textile 401 formulation (71 $\mu \mathrm{g}$ ECN) (D).

403 Experimental conditions were first optimized with the C. albicans SC5314 404 strain using the antifungal disk diffusion test [30]. Figure 5 shows a 405 representative setup for the experiment; ECN imprinted textiles were 406 compared to ECN standard disks, Pevaryl ${ }^{\circledR}$ deposited on filter paper, and 407 placebo composed of textiles imprinted with a blank formulation (i.e. same 408 composition, without ECN). The textile formulation demonstrated an 409 inhibition zone corresponding to $81 \%$ of that of the commercial formulation 410 on SC5314. The same experiment was repeated on a combination of 4 other $C$. 
411 albicans strains and the ECN textiles exhibited an inhibition of 93\% (Table 4).

412 These results showed that ECN maintained a roughly comparable activity on

413 textile as compared to the cream formulation. The slightly lower activity may

414 be due to the lower diffusion of ECN from the textile support. Pevaryl ${ }^{\circledR}$ might

415 also exhibit a slightly better efficacy because of its nanometer particle size

416 range, which increases surface area and facilitates diffusion, resulting in

417 increased drug activity [30]. These results were confirmed by assessing other

418 Candida species. ECN activity of ECN textiles reached 91\%, 84\% and 91\% of

419 the activity of the commercial formulation on $C$. lusitaniae, $C$. kefyr and $C$.

420 glabrata, respectively (Table 4). The activity was less important for C. krusei,

421 which often demonstrates an intrinsic resistance to azole drugs [31].

422

423 Table 4: Inhibition zone diameter (IZD) of ECN textile and Pevaryl ${ }^{\circledR}$ on

424 Candida spp and Trichophyton species after 18 hours at $32^{\circ} \mathrm{C}$

\begin{tabular}{lcccc}
\hline \multicolumn{1}{c}{ Strain } & Replicata & $\begin{array}{c}\text { IZD of ECN } \\
\text { Textile } \\
(\mathrm{mm})\end{array}$ & $\begin{array}{c}\text { IZD of } \\
\text { Pevaryl } \\
(\mathrm{mm})\end{array}$ & $\begin{array}{c}\text { Ratio } \\
\text { Textile/ } \\
\text { Pevaryl }^{\circledR} \\
(\%)\end{array}$ \\
\hline $\begin{array}{l}\text { C. } \text { albicans } \\
\begin{array}{l}\text { C. } \text { albicans } \\
\text { (4 Nantes Isolates) }\end{array}\end{array}$ & $\mathrm{n}=27$ & $18.8 \pm 0.9$ & $23.1 \pm 2.5$ & 81 \\
$\begin{array}{l}\text { C. lusitaniae } \\
\text { C. } \text { kefyr }\end{array}$ & $\mathrm{n}=8$ & $21.7 \pm 1.0$ & $23.4 \pm 1.9$ & 93 \\
C. glabrata & $\mathrm{n}=8$ & $18.5 \pm 0.7$ & $20.3 \pm 0.4$ & 91 \\
& $\mathrm{n}=8$ & $18.3 \pm 5.9$ & $19.5 \pm 4.2$ & 92
\end{tabular}




$\begin{array}{lcccc}\text { T. mentagrophytes } & \mathrm{n}=14 & 24.8 \pm 0.7^{\mathrm{a}} & 39.8 \pm 3.2^{\mathrm{a}} & 62^{\mathrm{a}} \\ \text { T. rubrum } & \mathrm{n}=3 & 29 \pm 1.7^{\mathrm{b}} & 47 \pm 4.2^{\mathrm{b}} & 62^{\mathrm{b}}\end{array}$

425 a IZD of textile formulation on T. mentagrophytes were measured after 4 days 426 at $25^{\circ} \mathrm{C}$

427 b IZD of textile formulation on T. rubrum were measured after 7 days at $25^{\circ} \mathrm{C}$.

429 Finally, inhibition of dermatophytes growth was examined on the two most 430 prevalent species in fungal skin infections, namely Trichophyton

431 mentagrophytes and T. rubrum $[12,13]$ (Table 3). In these latter tests, the

432 activity of ECN reached $62 \%$ of the commercial formulation activity. This lower

433 result could be explained by the temperature $\left(25^{\circ} \mathrm{C}\right)$ at which the experiment

434 was conducted. This temperature was selected for dermatophytes to grow

435 several days in vitro, but is lower than the fusion temperature of the

436 microparticles. At this temperature, ECN has a limited release, as shown in

437 figure 3, so that the effective concentration of ECN might have been lower than

438 the commercial formulation. Although the experimental conditions were not

439 adapted for the pharmaceutical textiles, similar results were obtained by

440 Hammer's et al. They concluded that T. mentagrophytes and T. rubrum were

441 less susceptible than C. albicans when exposed to antifungal textiles [13].

442 Overall, these results demonstrate that ECN textiles maintain their antifungal

443 activity against all azole-susceptible Candida species tested in vitro. Although

444 in vitro disk diffusion tests are not designed to test the long-term efficacy of 
445 controlled release products like the ECN textiles but rather immediate release,

446 this newly developed technology of imprinted textiles was shown to preserve

447 the pharmaceutical activity of the antifungal drug.

\section{$449 \quad 3.3$ Percutaneous absorption of ECN}

450 The impact of the lipid microparticle formulation on percutaneous absorption

451 was examined ex vivo by comparing the ECN textile to the commercial

452 formulation. Pig skin has been reported as a good model for skin percutaneous

453 absorption [32]. Commercial formulation was weighed on a filter paper to

454 provide the same ECN amount as ECN textile. Both ECN formulations were

455 applied upside down on pig skin for $24 \mathrm{~h}$ with the receptor fluid temperature

456 maintained at $37^{\circ} \mathrm{C}$ in the Franz diffusion cells. ECN was quantified by HPLC-

457 MS/MS in the different layers of the skin: SC, epidermis, dermis, and receptor

458 compartment (Figure 6). Overall percutaneous absorption was similar for both

459 formulations, showing that both systems diffused similar quantities of ECN.

460 This was in agreement with the comparable antifungal activity of both

461 treatments on Candida species (Table 4). Pevaryl's diffusion may be slightly

462 underestimated due to some absorption of ECN on the paper support.

463 Nevertheless, this partition would not have significantly impacted the total

464 release of econazole, which was less than $1 \%$ of the ECN loading. Other stimuli,

465 like friction, might further enhance drug delivery upon contact with the skin. 
466 Nevertheless, this reservoir effect of the textile was already observed for other

467 cosmetotextiles [8].

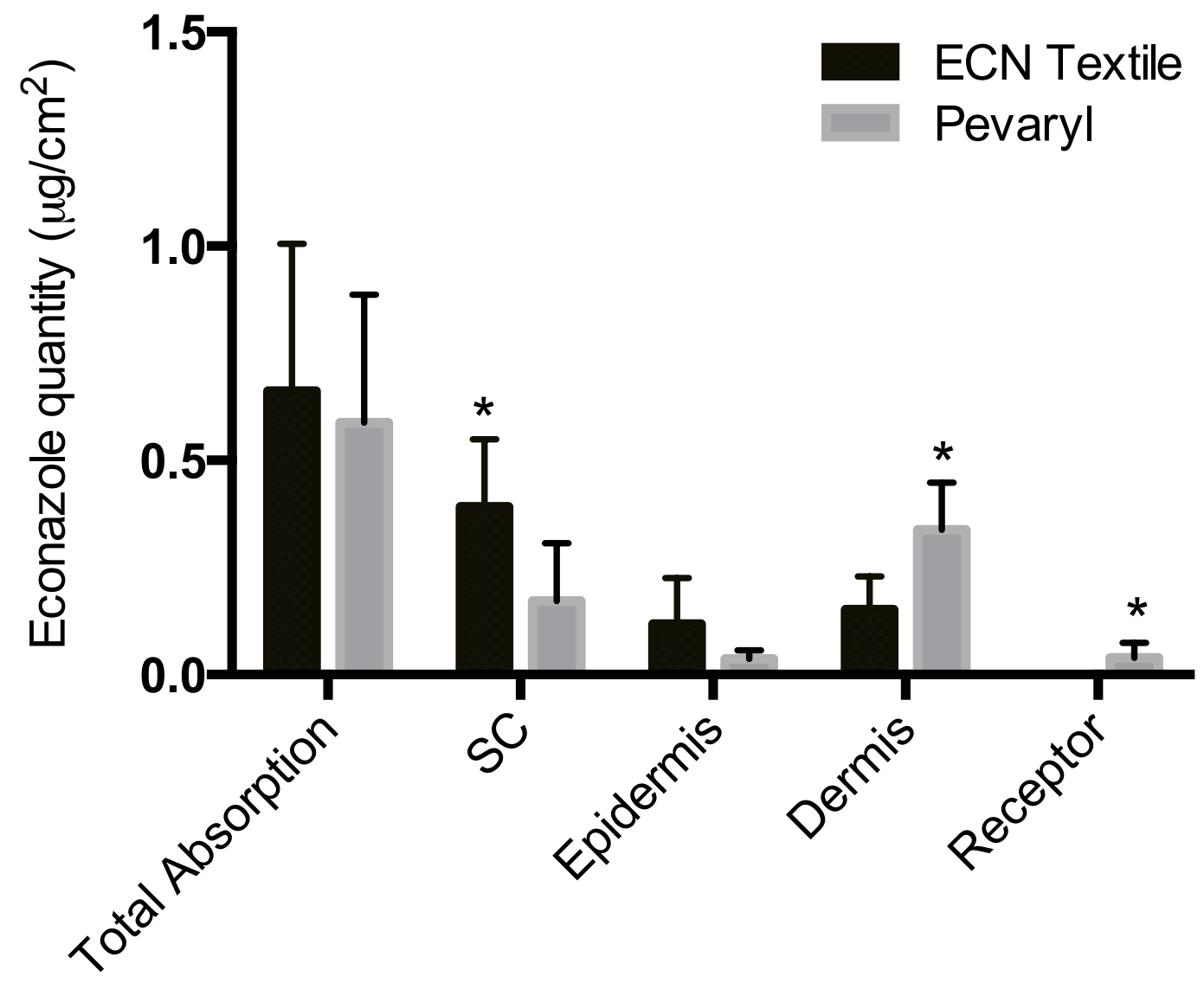

470 Figure 6: ECN content after 24 hour in Franz cells diffusion test on pig skin

471 using ECN textile (black bars) and Pevaryl ${ }^{\circledR}$ on filter paper (grey bars).

472 Receptor compartment was set at $37^{\circ} \mathrm{C}$. ECN quantification was done by LC473 MS/MS. Mean \pm standard deviation $(n=4)$. Asterisks indicate statistically 474 significant values $(\mathrm{p}<0.05)$. 
476 ECN skin distribution was slightly different between the ECN textile and the

477 commercial cream on filter paper. ECN from textiles was mainly distributed in

478 the SC and penetrated less in the epidermis and dermis, whereas ECN from the

479 commercial formulation was mainly found in the dermis and was even

480 quantifiable in the receptor compartment (Figure 6). This difference might be

481 attributed to the particle size of both formulations. Indeed, Pevaryl ${ }^{\circledR}$ was

482 determined to be a nano suspension whereas the particles deposited on the

483 textiles were in the micron range (Figures 1\&2). Nanometer formulations have

484 been reported to penetrate deeply into the dermis, and have also been used for

485 transcutaneous absorption of drugs [21]. In our case, the micrometer particles

486 were designed to concentrate into the upper layer of the skin, where the fungal

487 infections develop. Moreover, their lipid composition is thought to improve

488 their affinity for the skin tissues, resulting in a higher concentration of ECN in

489 the SC than the commercial formulation. This suggests that the pharmaceutical

490 textiles allowed for targeted delivery of active drug in the upper skin layers, as

491 observed for cosmetotextiles using microspheres [8, 21]. No ECN was

492 measured in the receptor compartment with the ECN textile, indicating that

493 systemic exposure was limited as compared to Pevaryl ${ }^{\circledR}$, which helps limiting 494 undesirable effects.

495

4963.4 Activity in a cutaneous candidiasis murine model 
497 The antifungal activity of ECN textiles was evaluated by challenging animals

498 with superficial fungal infection induced by C. albicans. The clinical strain used

499 for the experimental murine model was confirmed to be responsive to

500 econazole by the diffusion test (IZD $=25 \mathrm{~mm}$ and $31 \mathrm{~mm}$ for ECN textile and

501 commercial cream, respectively). ECN cream was applied daily, and textiles

502 (placebo or ECN) were replaced daily for 5 days. After 5 days of treatment,

503 effective infection by $C$. albicans was observed in the control group by

504 retroculture of biopsy samples (Figure 7). In contrast, the treatment with the

505 ECN textiles led to an important reduction of the yeast cutaneous burden,

506 which was also observed in the group treated with the ECN cream. This study

507 also highlighted that the textiles alone helped reducing of the burden.

508 However, no statistical significance could be concluded from this experiment,

509 since few mice from the control group were cured without any treatment,

510 probably because of incomplete immunosuppression. Nevertheless, wound

511 observation before and after treatment revealed that ECN textiles were well

512 tolerated and helped reducing the fungal burden without causing any irritation

513 (Figure 8).

514 


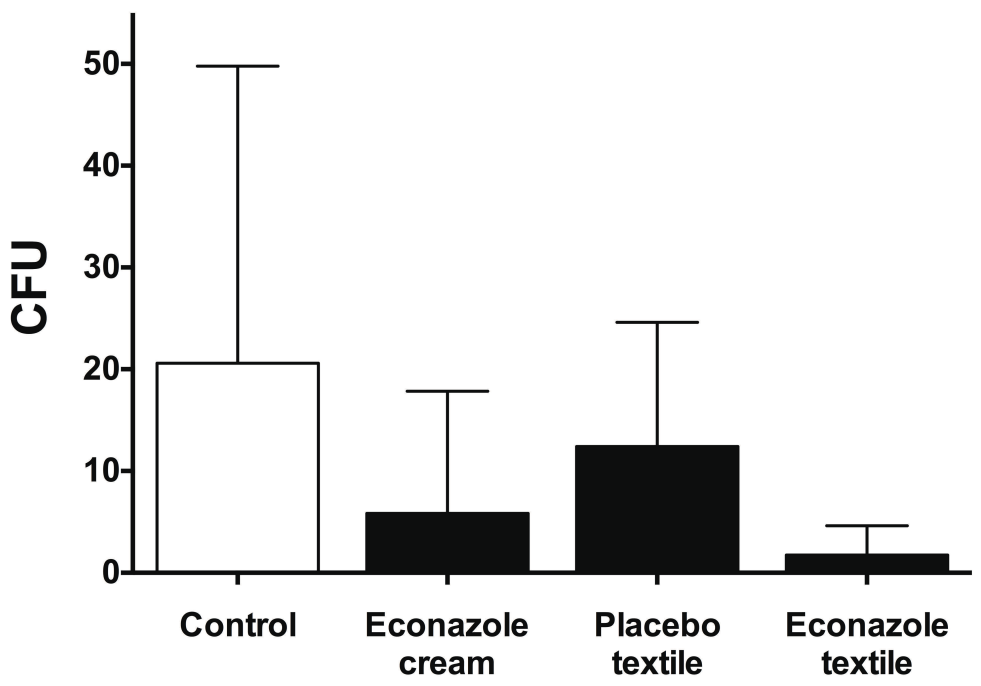

516 Figure 7. In vivo antifungal efficacy of pharmaceutical textiles, commercial

517 cream and placebo textiles. Evaluated by quantification of the fungal burden

518 (CFU) in skin biopsy samples. Mean \pm standard deviation $(n=6)$.

519

520

521 

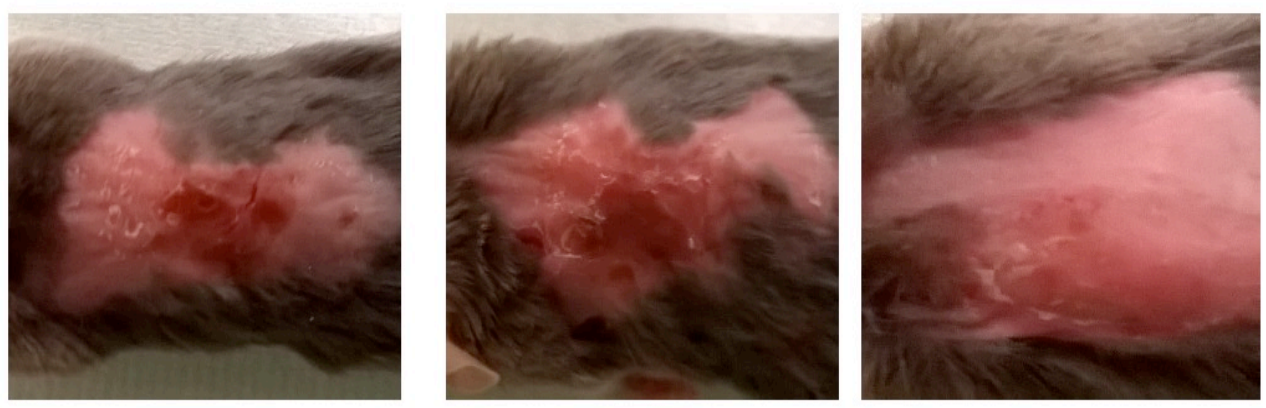

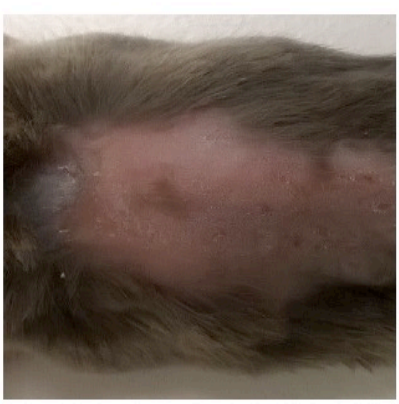

Econazole textile

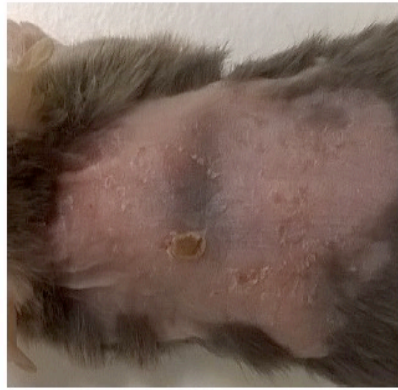

Econazole cream

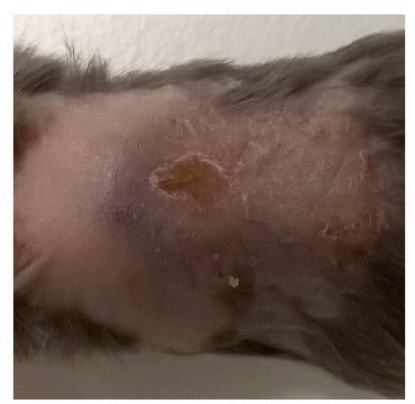

placebo

Figure 8: Representative cutaneous pathology pictures before (upper pannel)

524 and after treatment with ECN textiles, ECN cream or placebo textile (bottom

525 pannel).

526

527 4. Conclusion

528 This study was aimed at assessing pharmaceutical textiles using ECN as a

529 model drug for skin diseases. The technology of pharmaceutical textiles lies in

530 a dual innovation. Firstly, the thermo-sensitive microparticle formulation

531 ensured stability during storage and triggered thermo-sensitive release upon

532 contact with skin. The lipid microparticles allowed skin diffusion and drug

533 distribution within the upper layers of the skin, which is optimal to treat

534 superficial fungal infections and to prevent from systemic absorption. 
535 Secondly, the adapted screen-printing method adapted to the microparticle

536 drug formulation was able preserved the pharmaceutical activity of the drug.

537 ECN efficacy was maintained in vitro on a broad range of fungi strains and in

538 vivo, ECN textiles enabled high therapeutic efficacy against cutaneous

539 candidiasis in mice. Overall, these results revealed the potential this

540 technology to develop pharmaceutical textiles for the treatment of superficial

541 infections. Such textiles could be developed in bandages or socks, which,

542 through ease of use, would improve patient compliance.

\section{Acknowledgements}

544 The authors thank the Natural Sciences and Engineering Research Council of

545 Canada, Fonds de Recherche du Québec - Nature et technologies and Biomod

546 Concepts Inc. for their financial support. We thank Dr Fairbrother for providing

547 pig ears and Martin Jutras for developing the HPLC-MS/MS method.

\section{Conflict of interest.}

549 This work has been partially founded by Biomod Concepts Inc. The patented 550 technology belongs to Karine Théberge and Biomod Concepts Inc. All the 551 analyses and characterizations have been performed at the University of 552 Montreal or Nantes, independently from the company. 

from formulation to characterization: an overview, E-Polymers, (2010). [2] M.K. Singh, V.K. Varun, B.K. Behera, Cosmetotextiles: State of Art, 560 Fibres Text. East Eur., 19 (2011) 27-33.

561 [3] G. Nelson, Application of microencapsulation in textiles, Int. J.

562 Pharm., 242 (2002) 55-62.

563 [4] M. Karthikeyan, T. Ramachandran, O.L.S. Sundaram, 564 Nanoencapsulated phase change materials based on polyethylene glycol 565 for creating thermoregulating cotton, J. Ind. Text., 44 (2014) 130-146.

566 [5] M. Ibanescu, V. Musat, T. Textor, V. Badilita, B. Mahltig,

567 Photocatalytic and antimicrobial $\mathrm{Ag} / \mathrm{ZnO}$ nanocomposites for

568 functionalization of textile fabrics, J. Alloys Compd., 610 (2014) 244-

569249.

570 [6] J. Liu, C. Liu, Y. Liu, M. Chen, Y. Hu, Z. Yang, Study on the grafting of 571 chitosan-gelatin microcapsules onto cotton fabrics and its antibacterial 572 effect, Colloids Surf. B. Biointerfaces, 109 (2013) 103-108.

573 [7] C. Alonso, M. Marti, V. Martinez, L. Rubio, J.L. Parra, L. Coderch, 574 575 Antioxidant cosmeto-textiles: Skin assessment, Eur. J. Pharm. Biopharm., 84(2013) 192-199.

576 [8] M. Marti, V. Martinez, N. Carreras, C. Alonso, M.J. Lis, J.L. Parra, L.

577 Coderch, Textiles with gallic acid microspheres: in vitro release

578 characteristics, J. Microencaps., 31 (2014) 535-541.

579 [9] G. Cravotto, L. Beltramo, S. Sapino, A. Binello, M.E. Carlotti, A new

580 cyclodextrin-grafted viscose loaded with aescin formulations for a 581 cosmeto-textile approach to chronic venous insufficiency, J. Mater. Sci. 582 Mater. Med., 22 (2011) 2387-2395.

583 [10] C. Wiegand, U.C. Hipler, S. Boldt, J. Strehle, U. Wollina, Skin584 protective effects of a zinc oxide-functionalized textile and its relevance 585 for atopic dermatitis, Clin. Cosmetic Invest. Dermatol., 6 (2013) 115586121.

587 [11] R.J. Hay, N.E. Johns, H.C. Williams, I.W. Bolliger, R.P. Dellavalle, D.J. 588 Margolis, R. Marks, L. Naldi, M.A. Weinstock, S.K. Wulf, C. Michaud, J.L.M. 589 C, M. Naghavi, The global burden of skin disease in 2010: an analysis of 590 the prevalence and impact of skin conditions, J. Invest. Dermatol., 134 591 (2014) 1527-1534. 
592 [12] P. Vltavska, V. Kasparkova, R. Janis, L. Bunkova, Antifungal and 593 antibacterial effects of 1-monocaprylin on textile materials, Eur. J. Lipid 594 Sci. Technol., 114 (2012) 849-856.

595 [13] T.R. Hammer, H. Mucha, D. Hoefer, Dermatophyte susceptibility

596 varies towards antimicrobial textiles, Mycoses, 55 (2012) 344-351.

597 [14] C.W.M. Yuen, J. Yip, H.C. Cheung, L.W. Liu, C.H. Luk, W.C. Wai,

598 Treatment of interdigital-type tinea pedis with a 2-week regimen of

599 wearing hygienic socks loaded with antifungal microcapsules: A

600 randomized, double-blind, placebo-controlled study, J. Am. Acad.

601 Dermatol., 69 (2013) 495-496.

602 [15] R.C. Heel, R.N. Brogden, T.M. Speight, G.S. Avery, Econazole - Review

603 of its antifungal activity and therapeutic efficacy, Drugs, 16 (1978) 177-

604201.

605 [16] A. Brayfield, Martindale: The Complete Drug Reference, in: P. Press

606 (Ed.), MedicineComplete, 2014.

607 [17] M. Alsterholm, N. Karami, J. Faergemann, Antimicrobial activity of

608 topical skin pharmaceuticals - an in vitro study, Acta Derm. Venereol., $60990(2010) 239-245$.

610 [18] M. Gupta, S.P. Vyas, Development, characterization and in vivo 611 assessment of effective lipidic nanoparticles for dermal delivery of

612 fluconazole against cutaneous candidiasis, Chem. Phys. Lipids, 165 613 (2012) 454-461.

614 [19] B. Albertini, N. Passerini, M. Di Sabatino, B. Vitali, P. Brigidi, L. 615 Rodriguez, Polymer-lipid based mucoadhesive microspheres prepared 616 by spray-congealing for the vaginal delivery of econazole nitrate, Eur. J. 617 Pharm. Sci., 36 (2009) 591-601.

618 [20] Y.G. Bachhav, K. Mondon, Y.N. Kalia, R. Gurny, M. Moller, Novel 619 micelle formulations to increase cutaneous bioavailability of azole 620 antifungals, J. Control. Release, 153 (2011) 126-132.

621 [21] N. Passerini, E. Gavini, B. Albertini, G. Rassu, M. Di Sabatino, V.

622 Sanna, P. Giunchedi, L. Rodriguez, Evaluation of solid lipid

623 microparticles produced by spray congealing for topical application of

624 econazole nitrate, J. Pharm. Pharmacol, 61 (2009) 559-567.

625 [22] M. Gupta, S. Tiwari, S.P. Vyas, Influence of various lipid core on

626 characteristics of SLNs designed for topical delivery of fluconazole

627 against cutaneous candidiasis, Pharm. Dev. Technol., 18 (2013) 550-

628559.

629 [23] K. Theberge, J. Goudreault, F. Quirion, G. Perron, Articles of

630 manufacture releasing an active ingredient, International Intellectual 
631 Properties Patent no. 20100305209, (filed in US, Canada, Europe, China, 632 India, Australia, New Zealand, Brazil, Russia, Israel, Corea and South 633 Africa).

634 [24] I. Kazani, C. Hertleer, G. De Mey, A. Schwarz, G. Guxho, L. Van 635 Langenhove, Electrical Conductive Textiles Obtained by Screen Printing, 636 Fibres Text. East Eur., 20 (2012) 57-63.

637 [25] E. Skrzetuska, M. Puchalski, I. Krucinska, Chemically driven printed 638 textile sensors based on graphene and carbon nanotubes, Sensors 639 (Basel), 14 (2014) 16816-16828.

640 [26] T. Jones, N.A. Federspiel, H. Chibana, J. Dungan, S. Kalman, B.B.

641 Magee, G. Newport, Y.R. Thorstenson, N. Agabian, P.T. Magee, R.W. Davis, 642 S. Scherer, The diploid genome sequence of Candida albicans, Proc. Natl. 643 Acad. Sci. U S A, 101 (2004) 7329-7334.

644 [27] A.M. Gillum, E.Y. Tsay, D.R. Kirsch, Isolation of the Candida albicans 645 gene for orotidine-5'-phosphate decarboxylase by complementation of

646 S. cerevisiae ura3 and E. coli pyrF mutations, Mol. Gen. Genet., 198 647 (1984) 179-182.

648 [28] F. Quirion, D. Lambert, G. Perron, The Hlm method - a simple way to 649 get the solid liquid-phase diagrams and enthalpies of transition of pure 650 components and mixtures, Can. J. Chem., 70 (1992) 2745-2750.

651 [29] K. Kovacs, G. Stampf, I. Klebovich, I. Antal, K. Ludanyi, Aqueous 652 solvent system for the solubilization of azole compounds, Eur. J. Pharm. 653 Sci., 36 (2009) 352-358.

654 [30] A. Melkoumov, M. Goupil, F. Louhichi, M. Raymond, L. de

655 Repentigny, G. Leclair, Nystatin nanosizing enhances in vitro and in vivo 656 antifungal activity against Candida albicans, J. Antimicrob. Chemother., 65768 (2013) 2099-2105.

658 [31] S.S. Richter, R.P. Galask, S.A. Messer, R.J. Hollis, D.J. Diekema, M.A. 659 Pfaller, Antifungal susceptibilities of Candida species causing 660 vulvovaginitis and epidemiology of recurrent cases, J. Clin. Microbiol., 43 661 (2005) 2155-2162.

662 [32] C. Herkenne, A. Naik, Y.N. Kalia, J. Hadgraft, R.H. Guy, Pig ear skin ex 663 vivo as a model for in vivo dermatopharmacokinetic studies in man, 664 Pharm. Res., 23 (2006) 1850-1856.

665

666

667 